\title{
A atuação do enfermeiro na gestão do cuidado em reações transfusionais
}

\author{
The role of nurses in managing care in transfusion reactions
}

\author{
La actuación del enfermero en la gestión del cuidado en reacciones transfusionales
}

Walace Fernando Rocha de Souza1*, Eneida Tramontina Valente Cerqueira1.

\begin{abstract}
RESUMO
Objetivo: Contextualizar a atuação do enfermeiro na gestão de cuidados, suas capacidades técnicas e científicas frente à assistência de enfermagem nas reações transfusionais, de acordo com a literatura científica. Métodos: O presente estudo constitui-se de uma revisão da literatura, realizando-se consulta a livros e artigos científicos selecionados através de busca no banco de dados do Scielo e da Bireme, a partir das fontes Medline e Lilacs. Após a análise criteriosa, foram incluídos 6 (seis) artigos e utilizados os descritores: enfermagem; hemoterapia; reação transfusional. Resultados: A análise dos artigos selecionados revelou a deficiência nos conhecimentos relacionados à terapia transfusional, portanto, há necessidade de capacitação desde a graduação e da absorção de novos conhecimentos pelos diversos veículos educacionais. Numa perspectiva da camada metacontextual, reforça-se o desenvolvimento da hemoterapia. Portanto, é consensual, tanto da parte da enfermagem quanto dos usuários, que a saúde é um bem coletivo e, por isso, tem suas responsabilidades de ação preventiva e de inserção coletiva na melhoria do bem-estar de todos. Considerações Finais: Por serem os enfermeiros profissionais direta e constantemente envolvidos na gestão de cuidados, é fundamental que Ihes sejam garantidas formação e educação adequada, bem como atualizações e reciclagem regulares.

Palavras-chave: Enfermagem, Hemoterapia, Reação transfusional.
\end{abstract}

\section{ABSTRACT}

Objective: To contextualize the role of nurses in care management, their technical and scientific capacities regarding nursing care in transfusion reactions, according to the scientific literature. Methods: The present study consisted of a review of the literature, being carried out the consultation of books and scientific articles selected through an search in the database of Scielo and Bireme, from sources Medline and Lilacs. After a careful analysis, 6 (six) articles were included and the descriptors used: nursing; hemotherapy; transfusion reaction. Results: The analysis of the selected articles revealed a deficiency in the knowledge related to transfusion therapy, therefore, there is a need for training since graduation and absorption of new knowledge by the various educational vehicles. From a perspective of the metacontextual layer, the development of hemotherapy is reinforced. Therefore, it's consensual, on both parts of nursing and users, that health is a collective good and, therefore, has its responsibilities of preventive action and collective insertion in improving the wellbeing of all. Final Considerations: Because professional nurses are directly and consistently involved in care management, it's essential to provided them with adequate training and education, as well as regular updates and retraining.

Key words: Nursing, Hemotherapy, Transfusion reaction.

\section{RESUMEN}

Objetivo: Contextualizar la actuación del enfermero en la gestión de cuidados, sus capacidades técnicas y científicas frente a la asistencia de enfermería en las reacciones transfusionales, de acuerdo con la literatura científica. Métodos: El presente estudio se constituye en una revisión de la literatura, realizándose consulta a libros y artículos científicos seleccionados a través de búsqueda en el banco de datos de Scielo y Bireme, a partir de las fuentes Medline y Lilacs. Después del análisis cuidadoso, se incluyeron 6 (seis) artículos y utilizados los descriptores: enfermería; hemoterapia; reacción transfusional. Resultados: El análisis de los artículos seleccionados reveló la deficiencia en los conocimientos relacionados a la terapia transfusional, por lo tanto, hay necesidad de capacitación desde la graduación y la absorción de nuevos conocimientos por los diversos vehículos educativos. En una perspectiva de la capa metacontextual, se refuerza el desarrollo de la hemoterapia. Por lo tanto, es consensual, tanto por parte de la enfermería y de los usuarios, que la salud es un bien colectivo y, por eso, tiene sus responsabilidades de acción preventiva y de inserción colectiva en la mejora del bienestar de todos. Consideraciones finales: Por ser los enfermeros profesionales directos y constantemente involucrados en la gestión de cuidados, es fundamental que les sean garantizadas formación y educación adecuada, así como actualizaciones y reciclaje regulares.

Palabras clave: Enfermería, Hemoterapia, Reacción transfusional.

'Universidade São Judas Tadeu - Campus Unimonte, Santos-SP. *E-mail: walacefernando@hotmail.com

SUBMETIDO EM: 11/2018 ～～ACEITO EM: 12/2018 ～PUBLICADO EM: 3/2019 


\section{INTRODUÇÃO}

Os componentes do sangue e os seus derivados são utilizados como suporte para tratamento de inúmeras doenças e no apoio a transplantes, quimioterapia e cirurgias, tornando-se, assim, produtos essenciais e insubstituíveis. Mesmo havendo riscos por se tratar de produtos biológicos de origem humana, a hemotransfusão é parte essencial da atenção, promoção e recuperação da saúde (FERREIRA, 2007).

A enfermagem tem papel importante na garantia da segurança transfusional, pois a equipe é responsável por conhecer as indicações de transfusões, realizar a checagem de dados para prevenir erros, orientar os pacientes sobre a hemotransfusão, detectar e atuar no atendimento às reações transfusionais e documentar o procedimento (SILVA, 2009).

Tendo em vista a complexidade do processo transfusional e a necessidade de conhecimentos específicos em todo o seu desenvolvimento, esse processo exige profissionais habilitados e capacitados para que se alcance a segurança transfusional. O profissional de enfermagem está diretamente envolvido com os cuidados ao paciente que será submetido à transfusão; portanto, a instalação correta do sangue e sem erros na identificação depende muito da atuação da equipe de enfermagem, o que enfatiza a importância de que a equipe tenha conhecimentos científicos sobre transfusão e habilidade técnica, a fim de evitar a ocorrência de complicações e danos ao paciente (ÂNGULO, 2007).

A Lei 8080/90, que cria o SUS, já faz referência à área de Sangue e Hemoderivados, no que diz respeito à formulação e a execução da Política de Sangue e seus Derivados. A Lei 10.205/01, conhecida como "Lei Betinho" ou "Lei do Sangue" institui o Sinasan - Sistema Nacional de Sangue, Componentes e Derivados, e a Política Nacional de Sangue, Componentes e Hemoderivados. Tal política é dirigida pela Coordenação Geral de Sangue e Hemoderivados (CGSH) do Ministério da Saúde (BRASIL, 2013).

Conceitua-se hemovigilância como um conjunto de procedimentos de vigilância que abrange todo o ciclo do sangue, com o objetivo de obter e disponibilizar informações sobre os eventos adversos ocorridos nas suas diferentes etapas para prevenir seu aparecimento ou recorrência, melhorar a qualidade dos processos e produtos e aumentar a segurança do doador e receptor. Mesmo quando bem indicada, a transfusão sanguínea pode levar a reações adversas.

A reação transfusional pode ser definida como um efeito ou resposta indesejável observado em uma pessoa, associado temporalmente com a administração de sangue ou hemocomponente. Pode ser 0 resultado de um incidente do ciclo do sangue ou da interação entre um receptor e o sangue ou hemocomponente, um produto biologicamente ativo (MANUAL DE HEMOVIGILÂNCIA, 2013).

As agências transfusionais têm como papel assegurar uma terapia transfusional efetiva e livre de efeitos indesejados, entretanto, algumas reações transfusionais levam os pacientes a óbito. Dessa maneira, é imprescindível detectar, investigar e notificar sistematicamente as reações transfusionais dos serviços, de forma a introduzir medidas corretivas e preventivas para as reações decorrentes de falhas no processo do ciclo do sangue (MATOS et al., 2006).

A presente revisão, tem a finalidade de expor o papel do enfermeiro na gestão do cuidado em reações transfusionais, sendo a equipe de enfermagem detentora do contato direto e contínuo junto ao assistido.

\section{MÉTODOS}

O presente estudo constitui-se de uma revisão da literatura, realizando-se consulta a artigos científicos selecionados através de busca no banco de dados do Scielo e da Bireme, a partir das fontes Medline e Lilacs com os seguintes descritores: enfermagem, hemoterapia, reação Transfusional.

A pesquisa dos artigos foi realizada entre agosto e outubro de 2018. O critério de inclusão para os estudos encontrados foi a abordagem das condutas relacionadas ao enfermeiro na gestão de cuidados com o paciente em processo transfusional, em português e inglês, que estavam disponíveis online e na íntegra. O recorte temporal foi caracterizado pelos anos de 2013 a 2017.

\section{RESULTADOS}

Foram selecionados, de acordo com a temática 18 (dezoito) artigos e após análise 6 (seis) integraram o quadro de análise deste trabalho (Tabela 1). 
Tabela 1 - Caracterização dos estudos selecionados nas bases de dados.

\begin{tabular}{|c|c|c|c|}
\hline Autor/ano & Título & Objetivo & Conclusão \\
\hline $\begin{array}{l}\text { Sampaio; Maia; } \\
\text { Vasconcelos, } \\
\text { Freitas; Travassos } \\
\text { (2017) }\end{array}$ & $\begin{array}{l}\text { Terapia transfusional: } \\
\text { identificação dos } \\
\text { cuidados de } \\
\text { enfermagem }\end{array}$ & $\begin{array}{l}\text { Identificar os cuidados de } \\
\text { enfermagem realizados a } \\
\text { pacientes em terapia } \\
\text { transfusional. }\end{array}$ & $\begin{array}{l}\text { Os conhecimentos dos processos } \\
\text { devem ser monitorados, onde } \\
\text { possibilitem a implementação de ações } \\
\text { corretivas, objetivando sempre a } \\
\text { melhoria do serviço prestado. É } \\
\text { necessário rever a qualificação destes } \\
\text { profissionais e as medidas implantadas } \\
\text { para realização segura e eficaz do } \\
\text { procedimento. }\end{array}$ \\
\hline $\begin{array}{l}\text { Carneiro; Barp; } \\
\text { Coelho (2017) }\end{array}$ & $\begin{array}{l}\text { Hemoterapia e reações } \\
\text { transfusionais } \\
\text { imediatas: atuação e } \\
\text { conhecimento de uma } \\
\text { equipe de enfermagem }\end{array}$ & $\begin{array}{l}\text { Verificar o conhecimento } \\
\text { da equipe de } \\
\text { enfermagem sobre } \\
\text { hemoterapia, reações } \\
\text { transfusionais imediatas } \\
\text { e cuidados indicados } \\
\text { diante desses casos. }\end{array}$ & $\begin{array}{l}\text { É preciso que o profissional de } \\
\text { enfermagem busque mais } \\
\text { conhecimento e que as instituições } \\
\text { favoreçam esse aprendizado, } \\
\text { reconhecendo as fragilidades e as } \\
\text { potencialidades de sua equipe. }\end{array}$ \\
\hline $\begin{array}{l}\text { Lima; Silva; } \\
\text { Rocha; Barbosa } \\
(2016)\end{array}$ & $\begin{array}{l}\text { A importância do } \\
\text { enfermeiro durante a } \\
\text { reação transfusional } \\
\text { aguda: revisão da } \\
\text { literatura }\end{array}$ & $\begin{array}{l}\text { Contextualizar a atuação } \\
\text { do enfermeiro, suas } \\
\text { capacidades técnicas e } \\
\text { científicas frente à } \\
\text { assistência de } \\
\text { enfermagem na reação } \\
\text { transfusional aguda, de } \\
\text { acordo com a literatura } \\
\text { científica. }\end{array}$ & $\begin{array}{l}\text { Constata-se que a formação } \\
\text { acadêmica não supre integralmente as } \\
\text { necessidades da vida profissional, } \\
\text { havendo assim uma necessidade de } \\
\text { nova estruturação nas propostas e } \\
\text { processos de trabalho, tendo como } \\
\text { princípio que todo e qualquer } \\
\text { procedimento pertinente a saúde está } \\
\text { relacionado a algum tipo de risco, no } \\
\text { caso da transfusão que trata-se de um } \\
\text { processo complexo, requer } \\
\text { conhecimentos específicos. }\end{array}$ \\
\hline $\begin{array}{l}\text { Souza; Silva; } \\
\text { Maia; Gois; } \\
\text { Santos; Lima; } \\
\text { Nogueira (2015) }\end{array}$ & $\begin{array}{l}\text { Avaliando a assistência } \\
\text { de enfermagem na } \\
\text { hemotransfusão }\end{array}$ & $\begin{array}{l}\text { Avaliar a assistência de } \\
\text { enfermagem na } \\
\text { hemotransfusão. }\end{array}$ & $\begin{array}{l}\text { A principal dificuldade apresentada foi } \\
\text { a ausência de capacitação profissional } \\
\text { para a realização do procedimento. } \\
\text { Dentro desse contexto assistencial, a } \\
\text { educação continuada surge como uma } \\
\text { alternativa de reconstrução dos } \\
\text { conhecimentos relacionados à prática } \\
\text { da hemotransfusão. Acredita-se que } \\
\text { mediante a disponibilidade de } \\
\text { capacitações técnicas sobre a } \\
\text { temática, facilitariam a dinâmica da } \\
\text { realização do procedimento. }\end{array}$ \\
\hline $\begin{array}{l}\text { Cherem; Alves; } \\
\text { Rodrigues; } \\
\text { Pimenta; Souza; } \\
\text { Guerra (2014) }\end{array}$ & $\begin{array}{l}\text { Processo de terapia } \\
\text { transfusional em } \\
\text { unidade de terapia } \\
\text { intensiva neonatal: o } \\
\text { conhecimento do } \\
\text { enfermeiro }\end{array}$ & $\begin{array}{l}\text { Analisar o conhecimento } \\
\text { do enfermeiro da } \\
\text { Unidade de Terapia } \\
\text { Intensiva Neonatal } \\
\text { acerca do processo da } \\
\text { terapia transfusional }\end{array}$ & $\begin{array}{l}\text { Comprovou-se que os enfermeiros têm } \\
\text { conhecimento acerca do processo pré- } \\
\text { transfusional, embora alguns passos } \\
\text { importantes no cuidado não tenham } \\
\text { sido mencionados, mostrando a } \\
\text { necessidade de melhor capacitação } \\
\text { desses profissionais no cuidado } \\
\text { vinculado à terapia transfusional. }\end{array}$ \\
\hline $\begin{array}{l}\text { Silva; Vieira; } \\
\text { Silva; Ferreira } \\
(2013)\end{array}$ & $\begin{array}{l}\text { Desafios da } \\
\text { enfermagem diante das } \\
\text { reações transfusionais }\end{array}$ & $\begin{array}{l}\text { Avaliar o conhecimento } \\
\text { da equipe de } \\
\text { enfermagem diante das } \\
\text { reações transfusionais } \\
\text { em um hospital do } \\
\text { estado de Pernambuco. }\end{array}$ & $\begin{array}{l}\text { É necessária a realização de educação } \\
\text { continuada dos profissionais de } \\
\text { enfermagem a respeito da prática } \\
\text { transfusional. }\end{array}$ \\
\hline
\end{tabular}

Fonte: Dados da pesquisa, 2018. 


\section{DISCUSSÃO}

As discussões sobre segurança do paciente nas unidades hospitalares configuram uma tendência mundial e frequentemente tem sido abordado pela mídia questões que envolvem esta temática. A publicação do relatório do Institute of Medicine (IOM), To Err is Human: Building a Safer Health Care System, no final da década de 90 , demonstrou a partir da análise de grandes estudos epidemiológicos, a alta incidência de eventos adversos nas instituições hospitalares, frequentemente ocasionados pelo erro humano, passando a ser inegável a necessidade de repensar os modelos assistenciais utilizados, a fim de garantir a segurança do paciente (KOHN et al, 2011).

Sampaio et. al. (2017) afirma que o primeiro cuidado no pré-procedimento transfusional refere-se à confirmação da transfusão por meio da prescrição médica, com a sua indicação. Depois de ser realizada a confirmação completa com os dados do paciente, a etapa pré-transfusional começa com a solicitação médica e o encaminhamento do pedido, sendo realizada a coleta para a realização dos exames imunohematológicos, punção do acesso venoso periférico, aferição dos dados vitais e conferência do hemocomponente.

A Resolução do Conselho Federal de Enfermagem (COFEN) № 306/2006, dispõe as atribuições do enfermeiro em hemoterapia:

Artigo $1^{\circ}$ - Fixar as competências e atribuições do Enfermeiro na área de Hemoterapia, a saber: cumprir as normas e legislações vigentes, elaborar a prescrição de enfermagem nos processos hemoterápicos, executar, supervisionar, monitorizar a infusão de hemocomponentes e atuar nos casos de reações transfusionais adversas.

No contexto geral, o enfermeiro passou a se destacar atuando nas unidades hemoterápicas, no atendimento ao doador e ao receptor do sangue. Nesse sentido, houve um avanço para a enfermagem na área da hemoterapia no Brasil, iniciada na de 1990, quando os enfermeiros que atuavam na área de hematologia e hemoterapia passaram a discutir, em eventos científicos, o cuidado que o enfermeiro deveria prestar ao doador e ao receptor em todo o ciclo do sangue (FIDLARCZYK et al., 2008).

Ressalta-se que o enfermeiro atuante na assistência nos serviços de hemoterapia deve dominar 0 conhecimento técnico e cientifico dos eventos adversos que podem ocorrer na hemoterapia bem como a identificação de suas manifestações clínicas para que possa implementar ações sistematizadas de cuidado (SILVA et al., 2014).

Os conhecimentos práticos aliados ao científico conferem aos profissionais um conhecimento mais ampliado que permite uma assistência mais dinâmica e humanizada (TOREZAN \& SOUZA, 2010).

Neste ínterim é necessário que enfermeiro tenha uma visão holística da assistência, pois o cuidado individualizado qualifica a assistência da hemoterapia por permitir uma atenção direcionada às necessidades do paciente (SILVA e SOMAVILLA, 2010).

Carneiro et. al. (2017) realizou um trabalho para avaliar o conhecimento sobre hemoterapia e segurança transfusional de profissionais de enfermagem, onde demonstraram que mais da metade dos profissionais se sentiam pouco ou mal informado sobre o assunto e grande parte referiu que os pacientes não são orientados sobre sinais e sintomas de reações transfusionais.

Lima et al (2016) explicita que o profissional enfermeiro tem papel significativo na segurança transfusional trata-se não apenas da administração do hemocomponentes, mas sim de conhecer suas indicações, prevenir erros humanos e técnicos, orientar o paciente sobre o procedimento e por fim detectar, comunicar, notificar e atuar no atendimento das reações transfusionais e registrar todo o processo.

Conforme a RDC-ANVISA 57/10:

"Art. 152. Todo evento adverso ocorrido em receptores de sangue e hemocomponentes deve ser investigado e comunicado oficialmente à vigilância sanitária competente, por meio do sistema NOTIVISA, ou outro sistema que Ihe venha suceder". 
Entre as ações de hemovigilância implantadas associadas à ocorrência de incidentes transfusionais, destacamos a implantação do Notivisa, um sistema informatizado desenvolvido pela Agência Nacional de Vigilância Sanitária (Anvisa) para receber notificações de incidentes, eventos adversos e queixas técnicas relacionadas ao uso de produtos e de serviços sob vigilância sanitária. Seu preenchimento é de suma importância para que as estratégias de melhorias e adequações sejam embasadas em dados epidemiológicos gerados pela bioestatística, não devendo ser confundido somente como um sistema de informação, pois este envolve o processamento de dados e a análise quali-quantitativa e o envolvimento de interessados, que são os responsáveis pela sua interpretação, aliado aos demais mecanismos de comunicação. Evidencia-se que os estudos no campo da hemovigilância estão voltados à notificação e ocorrência dos diversos tipos de incidentes transfusionais, havendo necessidade de focalizar ações de prevenção, manejo adequado e tratamento de tais incidentes. A notificação dos eventos adversos é um instrumento essencial para o aperfeiçoamento da qualidade na hemoterapia e a subnotificação, atualmente, é o maior problema detectado pelo Sistema Nacional de Hemovigilângia. O formulário de notificação NÃO deve ser percebido como um mero instrumento burocrático. Os campos disponíveis foram estabelecidos com base na Classificação Internacional para Segurança do Paciente da Organização Mundial de Saúde (OMS), que proporciona o registro de dados para analisar cada caso notificado ou o conjunto de dados registrados por um serviço, em uma região ou no âmbito nacional e com isso possibilitar a avaliação das possíveis causas que provocaram o evento adverso (ANVISA, Boletim de Hemovigilância $n^{\circ} 4,2011$ ).

A detecção precoce de um evento adverso constitui estratégia para minimizar danos à saúde do paciente, é de extrema importância a intervenção profissional a ser efetuada o mais rápido possível, até porque ao administrar um hemocomponente, as reações transfusionais descritas podem ocorrer durante o processo, de forma imediata ou tardia. Sendo assim, é fundamental que o enfermeiro tenha conhecimento dos três "R": Reconhecer, Responder e Relatar reações transfusionais, para ser capaz de agir rapidamente (FREITAS et al., 2019).

Para a prática do enfermeiro nas unidades hemoterápicas públicas e privadas, houve a necessidade de uma legislação específica. Em março de 1997 o Conselho Federal de Enfermagem (COFEN) publicou a Resolução 200, que dispõe sobre a atuação do enfermeiro em hemoterapia e em transplante de medula óssea. Esta resolução foi atualizada e revogada pela Resolução 306/2006, que se encontra em vigor. Outro importante marco para a enfermagem hemoterápica diz respeito a criação do curso de Especialização nos Moldes de Residência de Enfermagem em Hematologia e Hemoterapia, em 2002 (SILVA et al., 213).

Numa perspectiva da camada metacontextual, reforça-se o desenvolvimento da hemoterapia. Portanto, é consensual, tanto da parte da enfermagem quanto dos usuários, que a saúde é um bem coletivo e, por isso, tem suas responsabilidades de ação preventiva e de inserção coletiva na melhoria do bem-estar de todos.

\section{CONCLUSÃO}

Por serem os enfermeiros profissionais direto e constantemente envolvidos no contexto da gestão de cuidados, é fundamental que Ihes sejam garantidas formação e educação adequada, bem como atualizações e reciclagem regulares. A identificação de reações transfusionais, conduta frente a elas e sua notificação devem estar atreladas para que todo processo seja efetivo. Para isso, o enfermeiro deve conhecer o processo por completo e ser capaz de intervir quando houver necessidade. Sugere-se que mais estudos sejam realizados para acrescentar as evidências científicas e assim subsidiar novas possibilidades de oferecer maior segurança aos clientes que necessitam de terapia transfusional, proporcionando uma assistência de qualidade, além de agregar novos conhecimentos aos profissionais de saúde que atuam nessa área. Salientase a necessidade do estímulo à cultura de segurança, o que permitirá discutir junto à equipe de enfermagem, estratégias de prevenção que assegurem a segurança do paciente e a gestão eficiente do cuidado nas instituições de saúde. 


\section{REFERÊNCIAS}

1. ÂNGULO IL. Hemoterapia moderna, práticas antigas. Rev Bras Hematol Hemoter. 2007,29(2):108.

2. BRASIL. Ministério da Saúde. Hemovigilância. Manual Técnico de Hemovigilância - Investigação das Reações Transfusionais Imediatas e Tardias Não Infecciosas. Brasília (DF): Anvisa; 2013.

3. BURMESTER H, PEREIRA JC, SCARPI, MJ. Modelo de gestão para organizações de Saúde. Rev Adm Saúde. 2007; 9(37):125-32.

4. COFEN. Conselho Federal de Enfermagem. Resolução COFEN no 306/2006. Normatiza a atuação do enfermeiro em hemoterapia. Rio de Janeiro: Conselho Federal de Enfermagem. 2006.

5. DANIELS G. Human Blood Groups. Blackwell Science. 2th ed. Oxford; 2002.

6. FERREIRA O, MARTINEZ EZ, MOTA CA, SILVA AM. Avaliação do conhecimento sobre hemoterapia e segurança transfusional de profissionais de enfermagem. Rev Bras Hematol Hemoter. 2007;29(2):160-7.

7. FIDLARCZYK D, FERREIRA SS. Enfermagem em hemoterapia. $1^{\underline{a}}$ ed. Rio de Janeiro (RJ): Medbook; 2008.

8. FREITAS BAC, FRANCESCHINI SCC. Fatores associados à transfusão de concentrado de hemácias em prematuros de uma unidade de terapia intensiva. Rev Bras Ter Intensiva. 2012;24(3):224-9.

9. GIANGRANDE PL.; The history of blood transfusion. British Journal of Haematology, Oxford, v.110, issue.4, p.758-767, September/2000.

10. HB BOLTON-MAGGS P. Blood transfusion safety: patients at risk from human errors. Br J Hosp Med (Lond). 2013;74(10):544-5.

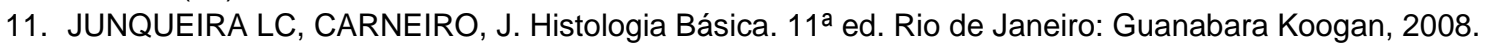

12. KOHN LT, CORRIGAN JM, DONALDSON MS. Committee on Quality of Health Care in America, Institute of Medicine. To err is human: building a safer health system

13. KUTNER JM.; KONDO, AT. Complicações das transfusões de produtos hemoterápicos. Revista Brasileira de Hematologia e Hemoterapia. 2012, 10(2).

14. MOLE LJ, HOGG G, BENVIE S. Evaluation of a teaching pack designed for nursing students to acquire essential knowledge for competent practice in blood transfusion administration. Nurse Educ Pract. 2007;7(4):228-37.

15. SILVA LAA; SOMAVILLA MB. Conhecimentos da equipe de enfermagem sobre terapia transfusional. Revista Cogitare Enfermagem, v. 15, n. 2 pág. 327-333, 2010.

16. SILVA MA, TORRES GV, MELO GSM, COSTA IKF, TIBURCIO MP, FARIAS TYA. Conhecimento da equipe de enfermagem no processo transfusional. Ciênc Cuidado Saúde. 2009;8(4):571-8.

17. SOARES A; NEVES M. Suporte hemoterápico ao paciente em emergência médica. Rev Med Minas Gerais. 2010; 20(4).

18. TOREZAN G, SOUZA EN. Transfusão de hemoderivados: os enfermeiros estão preparados para o cuidado peritransfusional. Revista: Rev. enferm. UFPE on line, v. 4, n. 2, p. 658-665, 2010. 